\section{Impact of FDG PET on the management of TBC treatment A pilot study}

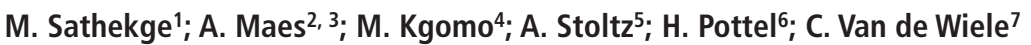 \\ ${ }^{1}$ Department of Nuclear Medicine, University of Pretoria, South-Africa; ${ }^{2}$ Department of Nuclear Medicine, AZ \\ Groeninge, Kortrijk, Belgium; ${ }^{3}$ Department of Morphology and Medical Imaging, University Hospital Leuven, Belgium; \\ ${ }^{4}$ Department of Internal Medicine, Louis Pasture Hospital, Pretoria, South-Africa; ${ }^{5}$ Department of Infectious Diseases, \\ University of Pretoria, South-Africa; ${ }^{6}$ Subfaculty of Medicine, Catholic University Leuven, Campus Kortrijk, Belgium; \\ ${ }^{7}$ Department of Nuclear Medicine, University Hospital Ghent, Belgium
}

Keywords

Tuberculosis, FDG PET, treatment, $\mathrm{CT}$, patient management

\section{Summary}

The aim of this study is to assess the potential impact of double-phase FDG PET versus routine staging in HIV-negative patients suffering from tuberculosis. Patients, methods: 16 consecutive patients suffering from tuberculosis underwent contrast-enhanced $\mathrm{CT}$ and double-phase FDG PET imaging (45 min, 120 min). Early (E) and delayed (D) SUVmax values were determined for all identified lesions and $\%$ change in SUV calculated ( $\triangle S U V$ ). Results: Seven patients presented with lung lesions on PET as well as CT (mean SUVmaxE 8.2 , mean SUVmaxD 11.1, $(p=0.002), \Delta S U V$ $35 \%$. In two patients, lesions were judged as non-active on CT. In nine patients, 18 sites of LN involvement were identified on both early and delayed FDG PET images (mean SUVmaxE 6.3, mean SUVmaxD 7.9, $(p=$ $0.0001), \triangle$ SUV: $25 \%$ ). 9 out of 18 sites of $L N$ involvement, occurring in five patients, were missed on CT. In four of these five patients, sites of LN involvement were the only sites of extra-pulmonary involvement identified. In 6 out of 16 patients, pleural involvement was identified, respectively in 5 on FDG PET and in 6 on $\mathrm{CT}$ imaging (mean SUVmaxE 1.3, mean

Correspondence to:

Prof. Dr. M. Sathekge,

University of Pretoria, Pretoria Academic Hospital,

Private Bag X169, Pretoria 0001, South-Africa

Tel. 01235417 94, Fax 0123541219

E-mail: mike.sathekge@up.ac.za
SUVmaxD 1.7, ( $p=0.06), \Delta$ SUV 21\%). In 4 patients, osseous involvement was identified by both FDG PET and CT (mean SUVmaxE 7.2, mean SUVmaxD 10.7, $(p=0,06), \triangle$ SUV $45 \%)$. Finally, in 3 patients, joint involvement was identified on both FDG PET as well as on CT imaging (mean SUVmaxE 4.7, mean SUVmaxD 5.2, $\triangle$ SUV 23\%). FDG PET did not identify CTadditional sites of involvement that would have resulted in a prolonged treatment. Conclusion: In HIV-negative patients suffering from tuberculosis, FDG PET images suggested a more extensive involvement by Mycobacterium tuberculosis when compared to contrast enhanced CT.

\section{Schlüsselwörter}

Tuberkulose, FDG-PET, Behandlung, CT, Patientenmanagement

\section{Zusammenfassung}

Ziel dieser Studie ist die Beurteilung eines möglichen Einflusses der 2-Phasen-FDG-PET im Vergleich zum Routine-Staging bei HIV-negativen Patienten mit Tuberkulose. Patienten, Methoden: Bei 16 aufeinanderfolgenden Patienten mit Tuberkulose wurden ein kontrastverstärktes CT sowie eine 2-Phasen-FDG-PET (45 min, $120 \mathrm{~min}$ ) durchgeführt. Frühe (E) und späte (D) SUVmax-Werte wurden für alle dargestellten

Einfluss der FDG-PET auf das therapeutische Vorgehen bei TBC - eine Pilotstudie Nuklearmedizin 2010; 49: 35-40 doi: 10.3413/nukmed-0270 received: September 2, 2009 accepted in revised form: December 15, 2009
Läsionen bestimmt; die prozentuale Veränderung der SUV ( $\triangle$ SUV) wurde berechnet. Ergebnisse: Bei sieben Patienten zeigten sich pulmonale Herde sowohl in der PET als auch im CT (mittlere SUVmaxE 8,2, mittlere SUVmaxD $11,1,(p=0,002), \Delta$ SUV 35\%). Bei zwei Patienten wurden die Läsionen im $\mathrm{CT}$ als nicht aktiv beurteilt. Bei neun Patienten wurde sowohl in den frühen als auch in den späten FDG-PET-Aufnahmen ein Lymphknotenbefall an 18 Stellen identifiziert (mittlere SUVmaxE 6,3 , mittlere SUVmaxD 7,9, $(p=0,0001)$, $\triangle$ SUV 25\%). Bei fünf Patienten fehlten im CT 9 der 18 befallenen Lymphknoten. Bei vier dieser fünf Patienten stellte der Lymphknotenbefall die einzige extrapulmonale Beteiligung dar. Bei 6/16 Patienten wurde eine pleurale Beteiligung festgestellt, bei 5 in der FDG-PET bzw. bei 6 im CT (mittlere SUVmaxE 1,3, mittlere SUVmaxD 1,7, $(p=0,06), \Delta$ SUV $21 \%)$. Bei 4 Patienten wurde eine Knochenbeteiligung sowohl in der FDG-PET als auch im CT diagnostiziert (mittlere SUVmaxE 7,2, mittlere SUVmaxD 10,7, ( $p=0,06), \Delta$ SUV $45 \%$ ). Schließlich wurde bei 3 Patienten ein Befall der Gelenke sowohl in der FDG-PET als auch im CT festgestellt (mittlere SUVmaxE 4,7, mittlere SUVmaxD 5,2, $\Delta$ SUV 23\%). In der FDG-PET konnte kein über das CT hinausgehender Befall festgestellt werden, der zu längerer Behandlungsdauer geführt hätte. Schlussfolgerung: Bei HIV-negativen Patienten mit Tuberkulose können die FDG-PET-Aufnahmen einen ausgedehnteren Befall mit $M y$ cobacterium tuberculosis vermuten lassen als das kontrastverstärkte CT. 
Tuberculosis is a systemic infection caused by Mycobacterium tuberculosis. It is transmitted by coughed aerosol and usually presents with respiratory symptoms (14, 22). While pulmonary tuberculosis is the most common presentation, tuberculosis can spread to virtually any tissue or organ of the body by haematogenous or lymphatic dissemination or contiguity (17). The most common sites of extra-pulmonary tuberculosis (EPTB) involvement (2, 12) are

- lymph nodes, followed by

- pleural effusion,

- bone and joint involvement.

Computerised tomography (CT) has proven to be a significant aids in the anatomical localisation of extra-pulmonary tuberculosis. In particular, for assessment of lymph node involvement, the finding of low-density lymph nodes with peripheral enhancement on a contrast-enhanced chest (CT appears to be highly predictive for tuberculosis $(8,23)$.

While FDG PET is reported to be a sensitive and specific technique in oncological imaging, it is well known that inflammatory and infectious lesions can cause falsepositive results $(3,4,16,18)$. Inflammatory cells such as macrophages, lymphocytes and neutrophil granulocytes as well as fibroblasts have been shown to avidly take up FDG, especially under active conditions. Both lymphocytes and especially macrophages are avidly present in sites of active tuberculosis. Therefore, FDG is also used as a tracer for infection imaging.

The aim of this study was to prospectively compare imaging results obtained by double-phase FDG PET to imaging results obtained by contrast CT in HIV negative patients suffering from active tuberculosis and to study the potential impact of FDG PET imaging on treatment planning.

\section{Patients, material, methods}

\section{Patients}

Sixteen consecutive patients either suffering from tuberculosis as proven by histology or sputum smear or presenting with a high clinical suspicion were prospectively included in the study following written informed consent. Seven patients suffered from pulmonary tuberculosis and nine from post-primary tuberculosis. None of them were on tuberculostatics at the time of the PET investigation. Approval for this study was granted by the Ethics Committee of the University Hospital of Pretoria.

Diagnosis of active tuberculosis was established by sputum microscopy and culture (5 patients), histological analysis of resected lymph nodes after FDG-PET imaging ( 7 patients) or on a clinical basis (4 patients; long-term follow-up of minimally six months with a favourable response to conventional tuberculostatics).

Criteria for clinical diagnosis were based on either CT findings suggestive of pulmonary tuberculosis (branching linear structures, satellite nodules, or a well-defined nodule with central calcification) that improved with antituberculous or based on a combination of the clinical aspects: prolonged cough lasting more than three weeks, chest pain and haemoptysis, low grade remittent fever, chills, night sweating, appetite or weight loss, easy fatigability, lymph node swelling and pleurisy that responded favourably to tuberculostatics.

\section{Dual-phase FDG PET/CT scanning}

Whole body ${ }^{18}$ FDG PET scans were acquired on a dedicated PET-CT scanner (Biograph, Siemens) from the skull top to the pelvis. Patients were required to be fasting for a minimum of four hours prior to FDG injection. Blood glycaemia was monitored with a portable capillary glucometer. Patients received a dose of FDG based on their body weight using the formula [(body weight/10)+1)] $37 \mathrm{MBq}$.

PET/CT imaging was performed $45 \mathrm{~min}$ and $120 \mathrm{~min}$ after injection of FDG. Acquisition duration per bed position was 3 min; nine bed positions were acquired.

Images were acquired in a 3-dimensional mode and reconstructed with and without attenuation correction (CT-based) using OSEM (ordered subset expectation maximization) yielding axial, sagittal and coronal slices. FDG PET images obtained were analyzed for the presence or absence of sites of active or inactive tuberculosis by two experienced nuclear medicine specialists, blinded to the clinical data and to the results obtained by morphological imaging. Disagreements were resolved by consensus.

For diagnostic CT scanning, the following parameters were used: collimation of $24 \times 1.2 \mathrm{~mm}$; gantry rotation time of 500 $\mathrm{ms}$; tube voltage of $120 \mathrm{kV}$; effective tube current of $100 \mathrm{mAs}$ with online tube current modulation and a table feed of $18 \mathrm{~mm} /$ rotation. Contrast enhancement was achieved by intravenous administration of $100 \mathrm{ml}$ of non-ionic contrast material (Ultravist) at a rate of $2 \mathrm{ml} / \mathrm{s}$. Matrix size was $512 \times 512$. CT-contrast-enhanced images were analyzed for the presence or absence of sites of active or inactive tuberculosis by two experienced radiologists blinded to the clinical diagnosis and FDG PET findings. Disagreements were resolved by consensus.

CT-criteria for joint infection: presence of joint effusion, juxta-articular osteoporosis, joint space narrowing, indistinctness of corical margins, marginal erosions and sclerotic reaction. CT-criteria for osteomyelitis: early soft tissue oedema, early periosteal reaction and focal erosions.

Subsequently, FDG-PET findings were compared to the diagnostic CT-results.

\section{Quantitative analysis}

SUVmax values were obtained for all lesions identified by drawing manually defined regions of interest on the attenuation-corrected early and delayed axial images. In case CT-findings were positive, the corresponding CT-image was used as anatomical landmark. From the SUVmax values percentage change in SUVmax from early to delayed images were calculated:

$$
\% \text { DSUVmax }=\frac{(\text { SUV maxD }- \text { SUVmaxE })}{\text { SUVmaxE }} \times 100
$$

\section{Statistical analysis}

Statistical analysis was performed using SPSS version 15.0. Differences in SUVmax from early to delayed imaging were determined using a two-tailed paired t-test. 
Tab. 1 Patients

\begin{tabular}{|c|c|c|c|c|c|c|c|c|c|c|c|}
\hline \multirow[t]{2}{*}{ patient } & \multirow[t]{2}{*}{ gender } & \multirow{2}{*}{$\begin{array}{l}\text { age } \\
\text { (years) }\end{array}$} & \multicolumn{3}{|l|}{ PET } & \multicolumn{3}{|l|}{$\mathrm{CT}$} & \multirow{2}{*}{$\begin{array}{l}\text { gold } \\
\text { standard }\end{array}$} & \multirow{2}{*}{$\begin{array}{l}\text { upstaging } \\
\text { by PET }\end{array}$} & \multirow{2}{*}{$\begin{array}{l}\text { therapeutic } \\
\text { impact }\end{array}$} \\
\hline & & & lung & lymph node & other & lung & lymph node & other & & & \\
\hline 1 & male & 33.5 & right side & mediastinal & - & right side & - & - & MC & + & - \\
\hline 2 & male & 32 & - & - & - & - & - & pleural & histology & - & - \\
\hline 3 & female & 32.5 & right side & - & - & right side & - & - & histology & + & - \\
\hline 4 & female & 68 & - & - & - & - & - & bone & histology & - & - \\
\hline 5 & female & 64.8 & both sides & - & - & - & - & bone & histology & + & - \\
\hline 6 & female & 52 & - & mediastinal & - & - & - & pleural & clinical & - & - \\
\hline 7 & female & 72 & - & - & - & - & - & joint & histology & - & - \\
\hline 8 & female & 82 & - & - & - & - & - & bone & histology & - & - \\
\hline 9 & male & 53.9 & - & $\begin{array}{l}\text { cervical, } \\
\text { mediastinal, } \\
\text { hilar }\end{array}$ & - & - & - & pleural & clinical & + & - \\
\hline 10 & female & 66 & - & cervical & - & - & - & bone & histology & + & - \\
\hline 11 & female & 35.6 & left side & $\begin{array}{l}\text { cervical, } \\
\text { axilar, } \\
\text { inguinal }\end{array}$ & - & left side & - & - & MC & - & - \\
\hline 12 & female & 1.5 & - & $\begin{array}{l}\text { axillar, } \\
\text { mediastinal, } \\
\text { hilar }\end{array}$ & - & - & axillar & - & MC & - & - \\
\hline 13 & male & 68.3 & right side & $\begin{array}{l}\text { mediastinal, } \\
\text { hilar }\end{array}$ & - & right side & - & - & clinical & + & - \\
\hline 14 & female & 49.6 & left side & - & - & left side & - & pleural & clinical & + & - \\
\hline 15 & female & 35 & both sides & - & - & both sides & - & - & MC & - & - \\
\hline 16 & male & 13.9 & - & - & - & - & - & joint & MC & - & - \\
\hline
\end{tabular}

MC: microscopy and culture

Differences in SUVmax values on early and delayed imaging as well as of percentage change in SUVmax between different locations were assessed using ANOVA and posthoc Bonferroni correction. Statistical significance was defined as $\mathrm{p}<0.05$.

Finally, the potential impact of FDG PET imaging as compared to CT on patient management was assessed.

\section{Results}

Mean age of the patients: 47.5 years (1.5-68.3 years). There were six men and ten women. Patient results are shown in $>$ Table 1.

\section{Lung involvement}

Out of the 16 patients included, 5 patients presented with a unilateral lung lesion on FDG PET (2 patients located in the left lung, 3 patients in the right lung) and 2 patients with a lung lesion on both sides. All lesions were correctly identified on the CTscan; in 2 patients, however, the lesions were judged to be non-active which was corroborated by the FDG PET findings.

The mean SUVmax of lung lesions on early images was 8.2 (range 3.4-21.7; SD 5.8), and 11.1 (range 4.5-27.2; SD 7.2) on late images. SUVmax values of lung lesions derived from delayed images were significantly higher when compared to those derived from early images $(p=0.002)$. The mean percentage change in SUVmax values was 35\% (range $23-54 \%$; SD 9.0\%).

\section{Lymph node involvement}

In 9 out of 16 patients, a total of 18 sites of LN involvement were identified on both early and delayed FDG PET images. 9/18 sites of LN involvement, occurring in 5 patients, were missed on CT. Thus, PET identified twice as much involved lymph nodes when compared to CT. These lesions were sub-centimetric in size and also did not display contrast enhancement. In 4 out of these 5 patients, the sites of $\mathrm{LN}$ involvement ( 8 in total) were the only sites of extra-pulmonary involvement identified ( $>$ Fig. 1, $>$ Fig. 2).

The mean SUVmax of positive LN on early images was 6.3 (range 3.4-9.2; SD 1.6) and 7.9 (range 4.7-10.9; SD 2.4) on late images. SUVmax values of positive lymph nodes derived from delayed images were significantly higher when compared to 


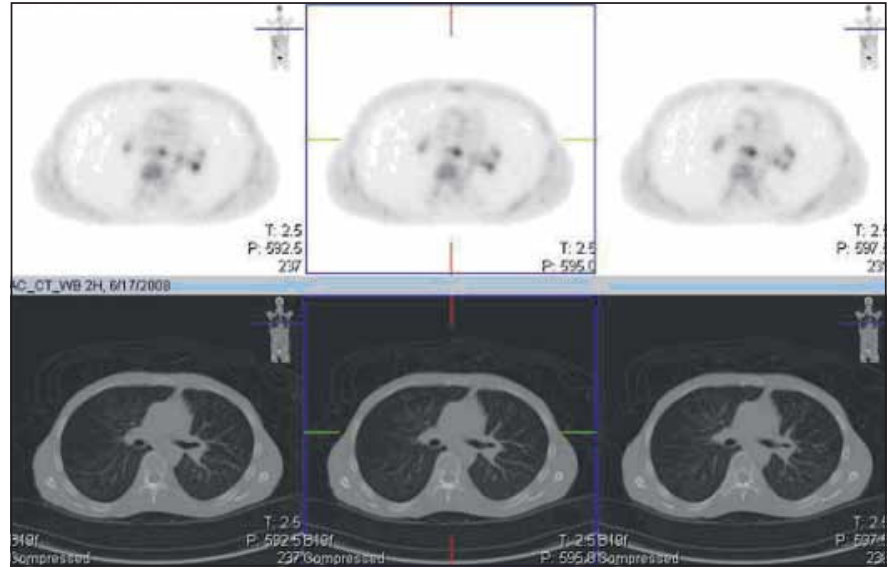

Fig. 1

FDG PET shows hypermetabolic mediastinal and hilar lymph nodes. At the same time $\mathrm{CT}$ is negative, demonstrating non-significant subcentimeter mediastinal nodes.

Fig. 2

Mediastinal and hilar nodes clearly positive on FDG PET images. CT proved negative. those derived from early images $(\mathrm{p}=$ $0.0001)$. The mean percentage change in SUVmax values was 25\% (range $8-52 \%$; SD $17.8 \%)$.

\section{Pleural involvement}

In 6 out of 16 patients, pleural involvement was identified, respectively in 5 patients on FDG PET and in 6 patients on CT imaging ( Fig. 3). The mean SUVmax of sites of pleural involvement on early images was 1.3 (range 0.7-1.7; SD 0.4), and 1.7 (range 0.9-2.3; SD 0.6) on late images. SUVmax values of sites of pleural involvement derived from delayed images showed a trend towards being higher when compared to those derived from early images $(p=0.06)$. The mean percentage change in SUVmax values was 21\% (range-25-43\%; SD 24\%).

\section{Osseous involvement}

In 4 patients, osseous involvement was identified by both FDG PET and CT separately, respectively in the sternum, in L4 and in Th7 and Th8 (Fig. 4). The mean SUVmax of sites of osseous involvement on early images was 7.2 (range 5.7-8.9; SD 1.3), and 10.7 (range 6.9-15.3; SD 3.6) on late images. SUVmax values of sites of osseous involvement derived from delayed images showed a trend towards being higher when compared to those derived from early images $(\mathrm{p}=0.01)$. The mean percentage change in SUVmax values was $45 \%$ (range $21-72 \%$; SD 25.5\%).

\section{Joint involvement}

Finally, in three patients, hip joint involvement was identified on both FDG PET as

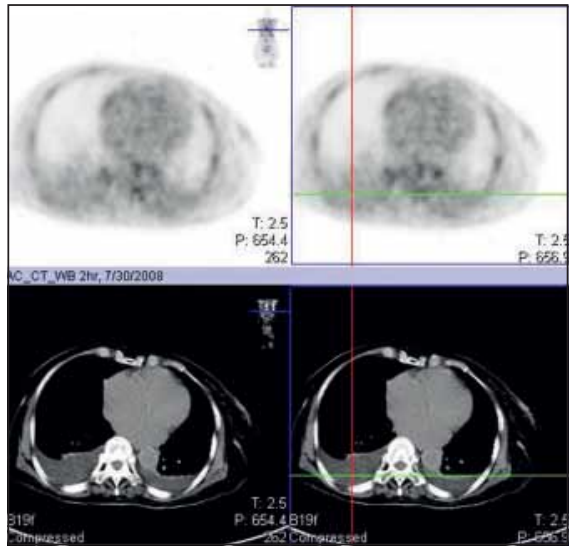

Fig. 3 Low grade FDG uptake in a pleural effusion

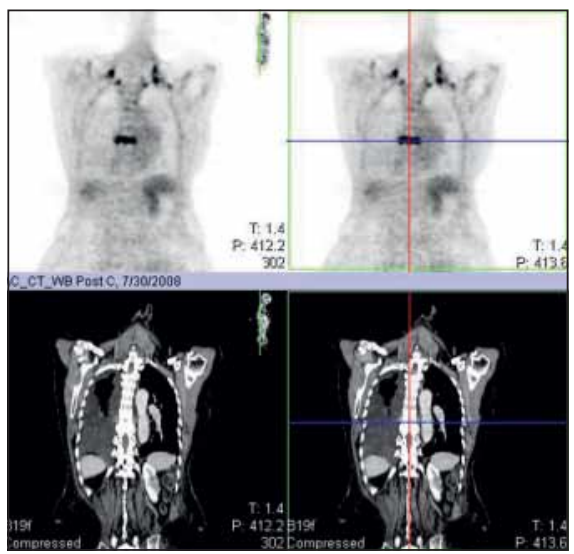

Fig. 4 FDG PET/CT findings in osseous involvement of Th8

well as on CT imaging, respectively in two patients on the right side and in one patient on the left side. The mean SUVmax of sites of joint involvement on early images was 4.7 (range 4.3-5.2; SD 0.5), and 5.2 (range 3.7-6.4; SD 1.4) on late images. The mean percentage change in SUVmax values was $23 \%$ (range-16-24\%; SD 22\%).

\section{FDG PET imaging}

FDG uptake was significantly lower on early images $(p \leq 0.01)$ as well as on delayed images $(p \leq 0.016)$ when compared to other sites of involvement. No difference was found between the percentage change in SUVmax for different locations.

Overall, while delayed imaging resulted in higher SUV values, no additional lesions were depicted on delayed versus early im- 
aging suggesting delayed imaging does not provide a diagnostic advantage in this patient population.

Finally, FDG PET imaging did not result in detection of additional sites of tuberculous involvement when compared to CTscanning that might have either warranted prolonged therapy, e. g. central nervous system and joint and bone tuberculosis or additional administration of corticosteroids e. g. tuberculous meningitis, tuberculous pericarditis or milliary tuberculosis .

\section{Discussion}

Data on FDG-PET imaging in patients suffering from tuberculosis are limited. Goo et al. studied ten consecutive patients suffering from histopathologically proved pulmonary tuberculosis (13). 9/10 tuberculomas showed FDG uptake at PET, and the mean SUVmax value was $4.2 \pm 2.2$ (SD). FDG uptake (range 1.9-3.7) in lesions adjacent to main abnormalities was demonstrated in four patients. The authors concluded that pulmonary tuberculoma commonly causes an increase in FDG uptake. More recently, Kim et al. evaluated the potential role of double phase acquisition of FDG PET for the differentiation of active pulmonary tuberculoma (19). A total of 25 consecutive patients with pulmonary tuberculoma were enrolled. PET/CT imaging was performed 60 (range 53-71) and 120 min (range 109-131) after injection of FDG. Early and delayed SUVmax values as well as \%DeltaSUVmax values were obtained in all patients. Active tuberculoma showed statistically significant higher values in maximal standardized uptake values than those of inactive tuberculoma:

- $\operatorname{SUV}(\operatorname{maxE})$ : active $2.3 \pm 0.75$, inactive $0.79 \pm 0.15$.

- $\operatorname{SUV}(\operatorname{maxD})$ : active $2.48 \pm 0.79$, inactive $0.75 \pm 0.13$

- \%DeltaSUV(max): active $8.07 \pm 7.77 \%$, inactive $-3.83 \pm 6.59$.

When SUV(maxE) 1.05 was used as the cut-off point, the sensitivity and specificity were 100 and $100 \%$. When SUV(maxD) 0.97 was used as the cut-off value, the sensitivity and specificity were 92.8 and $100 \%$. When \%DeltaSUV(max) 6.59 was used as the cut-off value, the sensitivity and specificity were 71.4 and $100 \%$.

The authors concluded that further studies are needed to confirm their results and improve statistical accuracy. In the series presented, 7 of 16 patients suffered from active lung tuberculosis. When compared to the series by Goo et al. and Kim et al., SUV max values in lung tuberculoma proved higher (mean values of respectively 8.2 (range 3.4-21.7) and 11.1 (range 4.5-27.2) (13, 19). Also, \%DeltaSUV(max) proved higher in this series when compared to the findings by Kim et al. (mean 35; range 23-54).

From a clinical point of view, the high SUV values and the SUV increase over time observed, are of concern when considering the specificity of cancer diagnosis in patients with solitary lung nodules. Hypothetically, the higher SUVmax values found in our series when compared to the studies by Goo et al. and Kim et al. may relate to a higher metabolic activity of macrophages in an attempt to control potentially more aggressive mycobacterium tuberculosis clones in an endemic region $(1,5-7,15)$. On the other hand, increased FDG uptake might hypothetically also be related to an increase in glucose uptake and metabolism by potentially more aggressive mycobacteria (9). Of interest, whereas all lung tuberculoma were identified on both CT and FDG PET, in two patients, lung lesions judged to be non-active on CT-scan proved active on FDG PET.

In agreement with literature, lymph nodes proved to be the most common site of extra-pulmonary involvement in our series, occurring respectively in 9 of $16 \mathrm{pa}$ tients $(2,12)$. Out of 18 sites of lymph node involvement identified by FDG PET in 9 patients, only 9 lymph nodes (5 patients) proved positive on contrast-enhanced CT and CT did not identify positive lymph nodes in the remaining 9 FDG PET LN negative patients. In 4 out of these 5 patients, the sites of LN involvement ( 8 in total) were the only sites of LN involvement identified.

Early SUVmax values were high (mean 6.3; range 3.4-8.7) and significantly increased over time (delayed SUVmax: mean 7.9; range 4.7-10.9): average increase in uptake of $25 \%$. While SUV values increased over time, delayed imaging, did, however, not result in the detection of additional lesions.

Our findings suggest that a more accurate assessment of the extent of lymph node involvement in patients suffering from extrapulmonary tuberculosis may be provided by means of FDG PET imaging when compared to contrast-enhanced CT alone.

Other sites of extra-pulmonary involvement identified on FDG PET in the series presented included in decreasing order of occurrence, pleural involvement, bone involvement and joint involvement respectively occurring in 6, 4 and 3 patients. Early and delayed SUVmax values were respectively $1.3(0.7-1.7)$ and $1.7(0.9-2.3)$ in pleural involvement, $7.2(5.7-8.9)$ and 10.7 (6.9-15.3) in bone involvement and 4.7 (4.3-5.2) and 5.2 (3.7-6.4) in joint involvement.

Tuberculosis pleuritis is caused by the rupture of a pulmonary subpleural caseous focus, which releases mycobacterium into the pleural cavity (26). The mycobacterial release triggers an immune response involving mainly macrophages and $\mathrm{CD} 4+\mathrm{T}$ lymphocytes ultimately resulting in the formation of an exudate. The low FDG SUVmax values as found in tuberculous pleural effusion in the series presented are comparable to those reported for other forms of benign exudates. In this regard, Duysinck et al. performed FDG PET in 79 patients with exudative pleurisy. SUVs were significantly higher in malignant pleural exudates $(n=51)$ when compared to benign exudates $(\mathrm{n}=28)(11)$. The cut-off value for SUV which gave the best accuracy $(82.3 \%)$ was 2.2. Similarly, FDG SUV uptake values obtained in bone and joint involvement proved comparable with FDG SUV uptake values reported previously in other forms of joint and osseous infectious involvement $(21,25)$.

Sites of extra-pulmonary tuberculosis involvement that warrant prolonged or extended therapy include involvement of the central nervous system and joint and bone tuberculosis (2, 12, 14, 17, 22). Also, adjunctive corticosteroid therapy is advocated in patients suffering from tuberculous meningitis, tuberculous pericarditis 
and miliary tuberculosis. While FDG PET suggested the existence of significantly more sites of tuberculosis involvement, additional sites revealed (predominantly lymph node involvement) did not result in an adjustment of treatment duration or the additional administration of corticosteroids in any of the patients under study. This finding, however, does not necessarily preclude a potential role for monitoring response to tuberculostatics in specific subsets of patients $(9,24)$.

Several authors have shown that the uptake of FDG continues to increase over time in malignant lesions whereas in benign lesions uptake decreases or remains stable over time $(20,27)$. Based on this finding, it was deduced that dual-time-point imaging might further improve the accuracy of FDG PET to distinguish benign from malignant disease. As suggested by this study, differentiation of sites of tuberculosis involvement from malignant involvement on the basis of dual-time point imaging may prove difficult.

\section{Limitations}

For ethical reasons it was impossible to perform biopsy and histologic analysis of the lesions identified by means of FDG PET. Accordingly, accuracy, sensitivity and specificity of FDG PET imaging for the assessment of the extent assessment of tuberculosis involvement could not be determined. However, histologic confirmation of lymph node involvement was obtained in seven patients. Additionally, in none of the patient studied was there evidence of a concomitant disease, e. g. HIV or an underlying malignancy, that might have been responsible for the high levels of FDG uptake found in pathologic sites identified. Finally, this pilot study included a limited number of patients and additional studies confirming our findings in larger series of patients are mandatory.

\section{Conclusion}

In this pilot study with HIV-negative patients suffering from tuberculosis, FDG PET images suggested a more extensive involvement by Mycobacterium tuberculosis when compared to contrast enhanced CT. While SUV values on delayed imaging proved significantly higher, no additional sites of involvement were depicted on delayed imaging.

For diagnostic purposes, early imaging in this patient population may suffice. FDG PET imaging did not change the treatment planning for any of our patients.

\section{Conflict of interest}

The authors declare, that there is no conflict of interest.

\section{References}

1. Adams D. The granulomatous inflammatory response: a review. Am J Pathol 1976; 84: 161-191.

2. Arciniegas W, Orjuela D. Extrapulmonary tuberculosis: a review of 102 cases in Pereira, Colombia. Biomedica 2006; 26: 71-80.

3. Bakheet S, Powe J. Benign causes of 18-FDG uptake on whole-body imaging. Semin Nucl Med 2000; 28 : 352-358.

4. Brown R, Leung J, Fisher S et al. Intratumoral distribution of tritiated fluorodeoxyglucose in breast carcinoma: are inflammatory cells important? J Nucl Med 1995; 36: 1854-1861.

5. Cameron R. Inflammation and repair. In: Robbins SL (ed). Pathology. Philadelphia, PA: WB Saunders 1967; 31-37.

6. Cazin M, Paluszezal D, Bianchi A et al. Effects of anaerobosis upon morphology and energy metabolism of alveloar macrophages cultured in gas phase. Eur Respir J 1990; 3: 1015-1022.

7. Dannenberg A, Tamashefski J. Pathogenesis of pulmonary tuberculosis. In: Fishman A, Elias J, Fishman J et al. (eds). Fishman's pulmonary disease and disorders. New York, NY: McGraw-Hill 1998; 2447-2471.

8. De Backer A, Mortelé K, De Keulenaer B, Parizel P. Tuberculosis: epidemiology, manifestations and the value of medical imaging in diagnosis. JBR-BTR 2006; 89: 243-250.

9. Demura Y, Tsuchida T, Uesaka D et al. Usefulness of 18F-fluorodeoxyglucose positron emission tomography for diagnosing disease activity and monitoring therapeutic response in patients with pulmonary mycobacteriosis. Eur J Nucl Med Mol Imaging 2009; 36: 632-639.

10. Deol P, Vohra R, Saini A, et al. Role of mycobacterium tuberculosis Ser/Thr kinase PknF: in glucose transport and cell division. J Bacteriol 2005; 187: 3415-3420.

11. Duysinck B, Larock M, Nguyen D et al. ${ }^{18} \mathrm{~F}-\mathrm{FDG}$ PET imaging in assessing exudative pleural effusions. Nucl Med Commun 2006; 27: 971-976.

12. Golden M, Vikram H. Extrapulmonary tuberculosis: an overview. Am Fam Physician 2005; 72: 1761-1768.

13. Goo J, Im H, Do K et al. Pulmonary tuberculoma evaluated by means of FDG PET: findings in 10 cases. Radiology 2000; 216: 117-121.

14. Grandjean L, Moore D. Tuberculosis in the developing world: recent advances in diagnosis with special consideration of the extensively drug-resistant tuberculosis. Curr Opin Infect Dis 2008; 21: 454-461.

15. Hara T, Kosaka N, Suzuki T et al. Uptake rates of 18 F-fluorodeoxyglucose and ${ }^{11} \mathrm{C}$-choline in lung cancer and pulmonary tuberculosis. Chest 2003; 124: 893-901.

16. Hellwig D, Baum RP, Kirsch CM. FDG-PET, PET/ $\mathrm{CT}$ and conventional nuclear medicine procedures in the evaluation of lung cancer - A systematic review. Nuklearmedizin 2009; 48: 59-69.

17. Jeong Y, Lee K. Pulmonary tuberculosis : up-to-date imaging and management. Am J Roentgenol 2008; 191: 834-844.

18. Kubota R, Yamada S, Kubota $\mathrm{K}$ et al. Intratumoral distribution of fluorine-18-deoxyglucose in vivo: high accumulation in macrophages and granulation tissues studied by microautoradiography. J Nucl Med 1992; 33: 1972-1980.

19. Kim I, Lee J, Kim S et al. Double-phase ${ }^{18} \mathrm{~F}$-FDG PET-CT for determination of pulmonary tuberculoma activity. Eur J Nucl Med Mol Imaging 2008; 35: 808-814.

20. Liu P, Huang G, Dong S, Wan K. Kinetic analysis of experimental rabbit tumour and inflammation model with ${ }^{18} \mathrm{~F}-\mathrm{FDG}$ PET/CT. Nuklearmedizin 2009; 48: 153-158.

21. Meller J, Sahlmann C, Liersch T et al. Non-prosthesis orthopaedic applications of ${ }^{18} \mathrm{~F}$ fluoro-2-deoxyD-glucose PET in the detection of osteomyelitis. Radiol Clin North Am 2007; 45: 719-733.

22. Pai M, O’Brien R. New diagnostics for latent and active tuberculosis : state of the art and future prospects. Semin Respir Crit Care Med 2008; 29: 560-568.

23. Parron M, Torres I, Pardo M et al. The halo sign in computed tomography images: differentiation and correlation with pathology findings. Arch Bronconeumol 2008; 44: 386-392.

24. Reuter S, Grüner B, Buck AK et al. Long-term follow-up of metabolic activity in human alveolar echinococcosis using FDG-PET. Nuklearmedizin 2008; 47: 147-152.

25. Strobel K, Stumpe K. PET/CT in musculoskeletal infection. Semin Musculoskelet Radiol 2007; 11: 353-364.

26. Valdés L, Pose A, San José E, Martinez Vazquez J. Tuberculous pleural effusions. Eur J Intern Med 2003; 14: 77-88.

27. Zhuang H, Pourdehnad M, Lambright ES et al. Dual time point ${ }^{18} \mathrm{~F}$-FDG PET imaging for differentiating malignant from inflammatory processes. J Nucl Med 2001; 42: 1412-1417. 